\title{
El complejo dinamismo del Derecho de Familia en Chile. Reseña del libro de Castillo Saldías, Alicia: Manual práctico de Derecho de Familia. Santiago, Editorial Metropolitana, 2019, 308 PP.
}

\section{The difficult dynamism of the family law in Chile. ReView of the booK by Castillo Saldías, Alicia: Manual práctico de Derecho de Familia. Santiago, Editorial Metropolitana, 2019, 308 Pp.}

Nicolás Amadiel lbáñez Meza* Trabajo recibido el 15 de diciembre de 2019 y aprobado el 16 de diciembre de 2019

\section{ResUMEN}

El derecho en sus distintas áreas va cambiando para lograr ajustarse a las situaciones que la sociedad demanda, lo que en el caso del derecho de familia cobra especial relevancia considerando las grandes reformas que se han implementado en los últimos quince años y asimismo, de lo evidenciable de las reformas en el cambio de vida de las personas. De la reforma a la regulación del matrimonio, hasta la introducción del acuerdo de unión civil en el año 2016, las leyes se han ido ajustando, intentando mantener cierta armonía, tarea compleja considerando las múltiples normas que se utilizan en el diario para resolver conflictos de tal naturaleza y es precisamente en ello en la que este libro brinda gran ayuda.

Palabras clave: Derecho de Familia, Manual Práctico, Litigación de Familia

\begin{abstract}
The law in its different areas is changing to be able to adjust to the situations that society demands, which in the case of family law becomes especially relevant considering the great reforms that have been implemented in the last fifteen years and also, of the importance of these reforms in the change of people's lives. From the reform to the regulation of marriage, until the introduction of the civil union agreement in 2016, the laws have been adjusted, trying to keep a certain harmony, a complex task considering the multiple norms that are used everyday to resolve conflicts of such nature and it is precisely in that, than this book provides a great help.
\end{abstract}

Keywords: Family Law, practice book, Family law litigation.

\footnotetext{
Nicolás Amadiel Ibáñez Meza. Abogado. Magíster en Docencia Universitaria, Universidad Autónoma de Chile. Profesor jornada completa Derecho Civil y Familia, Sede Santiago, Facultad de derecho, Universidad Autónoma de Chile. Correo de contacto: nicolas.ibanez@uautonoma.cl
} 


\section{Contextos y fundamentos de la normativa vigente del Derecho de Familia.}

El derecho de familia chileno se caracteriza por tener una importante influencia de derecho romano y de las codificaciones liberales del siglo XIX, en el que se utiliza la ley como principal fuente del derecho', lo que implicó al caso chileno, que el texto del Código Civil amparó su regulación, considerándose como una arista de este derecho privado dentro de su amplitud. Siendo innegable el carácter -literalmente- privado de las relaciones familiares, es dable señalar que la aplicación de sus normas trasciende a la relación acreedor y deudor propio de la relación patrimonial civilista, lo que provocó que desde su origen se pusiera en tela de juicio el que el derecho de familia fuese en realidad Derecho Civil2 a an cuando estuviera gran parte de su regulación tratado en el Código de la materia.

Si a esta situación se agrega el reconocimiento de la familia en el texto constitucional, en cuanto se establece como el núcleo fundamental y luego, invocando su protección y fortalecimiento como uno de los fines del Estado³, se complejiza la clasificación de esta rama del derecho, ya que también habrán normas de derecho público que regularían a la familia, lo que hizo entenderle de forma un tanto confusa como un derecho intermedio entre el derecho público y el derecho patrimonial, y no comprendiéndose si en realidad era derecho público o derecho privado ${ }^{4}$. Así, si se analiza la situación actual del derecho de familia, sería dable caracterizarlo como una rama mixta, en la que, según la materia y sujetos involucrados, habrá que atender los límites de aplicación, sean del derecho privado o del derecho público. De esta forma se está, por una parte, por una cierta tendencia a la desregulación al entregar a sus miembros los poderes de disciplina de una serie de sectores, tradicionalmente reservados a la ley y, por otra, una clara tendencia a la hiper-regulación de sectores tradicionalmente ajenos a las preocupaciones estatales ${ }^{5}$. Dentro del primer grupo, puede ubicarse a las materias relativas a la separación de los cónyuges, y dentro del segundo, a las materias de vulneración de derechos de niños, niñas y adolescentes. Esta distribución se justifica por el denominado principio de mínima intervención del Estado en el derecho de familia, según el cual el Estado no puede intervenir a través de sus órganos en la familia contra la voluntad de la propia unidad familiar, sino en casos graves o extremos ${ }^{6}$, es decir, que el Estado ostenta un rol meramente subsidiario, debiendo desarrollar las políticas de fomento y protección necesarias, e interviniendo únicamente de forma directa en la relación familiar en última instancia?.

A mayor abundancia, el derecho de familia en su intento constante de especialización y diferenciación de la regulación puramente civilista, se ha ido estructurando a través de múltiples normas, las que, al no estar en un solo cuerpo normativo, dificultan la comprensión orgánica de las relaciones que regula. Así y sólo por nombrar algunas leyes, sumado al Código Civil, el estudiante, abogado y juez de familia debe utilizar una ley especial para matrimonio, alimentos, violencia intrafamiliar, para protección de niños, niñas y adolescentes, adopción y procedimientos en tribunales de familia ${ }^{8}$. Es este el escenario en que la doctrina busca hacer sus aportes, y dentro del cual se enmarca la obra que entrega la profesora CASTILL. Tal como señala, en sus líneas busca abordar los diferentes ámbitos de esta disciplina y permitir

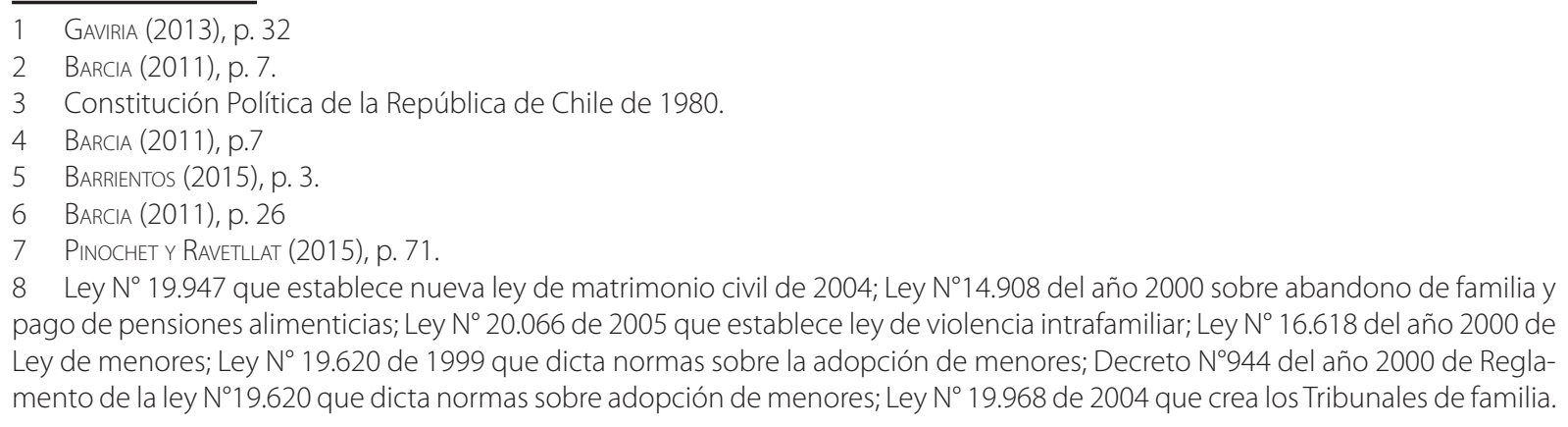
pago de pensiones alimenticias; Ley N²0.066 de 2005 que establece ley de violencia intrafamiliar; Ley Nº 16.618 del año 2000 de Ley de menores; Ley N 19.620 de 1999 que dicta normas sobre la adopción de menores; Decreto №44 del año 2000 de Reglamento de la ley N¹9.620 que dicta normas sobre adopción de menores; Ley Nº 19.968 de 2004 que crea los Tribunales de familia. 
dar respuesta adecuada a las interrogantes que se presentan en casos prácticos ${ }^{9}$, situándose en diversas áreas comunes de la litigación y la enseñanza aplicando el criterio y la mixtura de normas requeridas al efecto.

\section{Utilidad o uso del manual práctico de Derecho de Familia.}

Distribuido en cuatro partes o capítulos, todos atingentes al Derecho de familia, la obra de la Profesora Castillo viene en resolver de forma integral la aplicación de las normas en materia de Alimentos, cuidado personal, relación directa y regular, patria potestad, compensación económica y violencia intrafamiliar. El enfoque dado destaca por la razón que no se centra solamente en las determinaciones de fondo de las normas, sino también en sus nociones procesales que facilitan la comprensión y aplicación a la hora de enfrentar un juicio que tenga como objeto alguna de las materias antes indicadas.

En lo relativo a los alimentos, analiza en conjunto la normativa del propio Código Civil con la aplicación de la ley № 14.908 sobre abandono de familia y pensiones de alimentos y de la ley Nº 19.968 que crea los Tribunales de Familia, pudiendo responder interrogantes que van desde la legitimidad activa para demandar alimentos hasta la forma de cumplimiento y ejecución de las sentencias. Luego, en la segunda parte, del cuidado personal, relación directa y regular y patria potestad, conjuga la normativa del Código Civil y su reforma del año 2013 por la ley № 20.680 con la protección dada por la Convención sobre Derechos del Niño y, asimismo, por la ley de menores $N^{0} 16.618$, cerrando nuevamente con las determinaciones procesales tales materias.

Ya en la tercera parte, relativa a compensación económica, la autora expone las determinaciones de fondo otorgadas esta vez por la ley № 19.947 que establece nueva ley de matrimonio civil, analizando pormenorizadamente los requisitos de la institución en comento, para luego, siguiendo la misma técnica antes indicada, proveer la explicación procesal de la misma conforme a la ley № 19.968 que crea los Tribunales de Familia. Para finalizar, se analizará en la misma forma antes establecida, es decir, tanto en sus nociones de forma como de fondo, a la ley № 20.066 de Violencia Intrafamiliar.

La valiosa obra de la profesora Castillo es una seria contribución a la formación y profesionalización de la litigación del derecho de familia en Chile, y de ahí lo deseable de trabajo futuro en que desarrolle en la misma técnica de escritura, de simplicidad en la explicación, pero de integralidad en el tratamiento, otras importantes materias del área que han quedado pendientes, como la autorización de salida del país de niños, niñas y adolescentes, divorcio y nulidad matrimonial, acciones de filiación y causas de protección de derechos de niños, niñas y adolescentes.

\section{Bibliografía}

Barcia Lehmann, Rodrigo (2011): "Fundamentos del Derecho de Familia y de la infancia" (Santiago, Thomson Reuters Puntolex).

Barrientos Grandón, Javier (2015): "Código de la Familia" (Santiago, Thomson Reuters).

Castlllo Saldías, Alicia (2019); "Manual Práctico de Derecho de Familia" (Santiago, Editorial Metropolitana)

9 CASTLLo (2019), p. 5.

IBÁÑEZ MEZA, Nicolás Amadiel. El complejo dinamismo del Derecho de Familia en Chile. Reseña del libro de Castillo Saldías, Alicia: Manual práctico de Derecho de Familia. Santiago, Editorial Metropolitana, 2019, 308 pp. Revista Justicia y Derecho, Santiago, v. 2, n², 2019 
GAVIRIA GIL, María Virginia (2013): "El derecho occidental del siglo XXI y el concepto de familia jurídica", Revista de Derecho Universidad del Norte, Colombia, N³9: pp. 30-57.

Pinochet Olave, Ruperto y Ravetllat Ballesté, Isaac (2015): “El Principio de mínima intervención del Estado en los asuntos familiares en los sistemas normativos chileno y español", Revista de Derecho de la Pontificia Universidad Católica de Valparaíso, Vol. XLIV: pp. 69-96.

IBÁÑEZ MEZA, Nicolás Amadiel. El complejo dinamismo del Derecho de Familia en Chile. Reseña del libro de Castillo Saldías, Alicia: Manual práctico de Derecho de Familia. Santiago, Editorial Metropolitana, 2019, 308 pp. Revista Justicia y Derecho, Santiago, v. 2, n², 2019 